\title{
Establishing New Capability of High Temperature Electrochemical Impedance Spectroscopy Techniques for Equilibrium and Kinetic Experiments
}

\author{
Hongqiang $\mathrm{Hu}$ \\ Claire Xiong \\ Mike Hurley \\ Ju Li
}

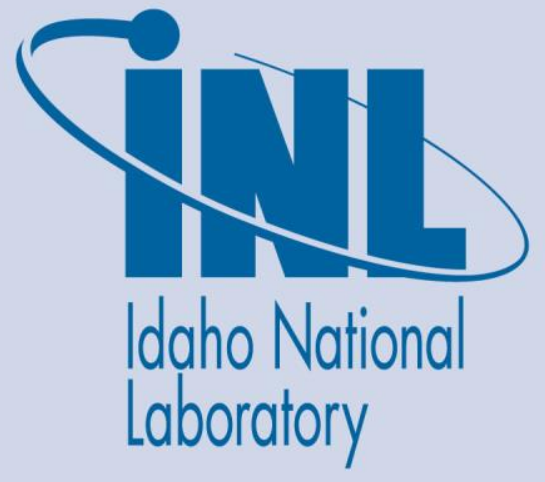

December 2017

The INL is a U.S. Department of Energy National Laboratory operated by Battelle Energy Alliance 


\section{DISCLAIMER}

This information was prepared as an account of work sponsored by an agency of the U.S. Government. Neither the U.S. Government nor any agency thereof, nor any of their employees, makes any warranty, expressed or implied, or assumes any legal liability or responsibility for the accuracy, completeness, or usefulness, of any information, apparatus, product, or process disclosed, or represents that its use would not infringe privately owned rights. References herein to any specific commercial product, process, or service by trade name, trade mark, manufacturer, or otherwise, does not necessarily constitute or imply its endorsement, recommendation, or favoring by the U.S. Government or any agency thereof. The views and opinions of authors expressed herein do not necessarily state or reflect those of the U.S. Government or any agency thereof. 


\title{
Establishing New Capability of High Temperature Electrochemical Impedance Spectroscopy Techniques for Equilibrium and Kinetic Experiments
}

\author{
Hongqiang $\mathrm{Hu}$ \\ Claire Xiong \\ Mike Hurley \\ Ju Li
}

December 2017

Idaho National Laboratory Idaho Falls, Idaho 83415

http://www.inl.gov

Prepared for the U.S. Department of Energy Office of Nuclear Energy Under DOE Idaho Operations Office Contract DE-AC07-05ID14517 



\section{EXECUTIVE SUMMARY}

In nuclear fuel and cladding materials, changes in structure and chemistry over the lifetime of the fuel can have a significant impact on fuel and reactor performance. Currently, chemical evolution over the lifetime of the fuel can only be inferred using post-irradiation examination. As an alternative to post-irradiation measurements, electrochemical impedance spectroscopy (EIS) can provide an in-pile measurement of changes in chemistry in oxides and hydrides coupling with modeling such as finite element (FE) and other material characterization techniques such as atom probe tomography (APT), Raman spectroscopy, in-situ Transmission Electron Microscopy (TEM), and synchrotron X-ray microscopy. The objective of this work package is to develop EIS techniques for the in-pile measurement of changes in solid state chemistry of fuels and materials in coupling with model simulation and material characterization. This work package will involve the initial development of electrochemical sensing technologies for measuring spatial- and time-resolved changes in fuel and cladding chemistry. Specific attention will be paid to monitoring changes in fuel stoichiometry, monitor cladding hydride formation and deformation, and cladding corrosion.

This report summarized the FY17 achievements of this work package. A laboratory was begun to set up from scratch. The laboratory place was located; necessary equipment and materials were purchased and some were delivered; laboratory instruction (LI) for conducting experiments was drafted for review; radiation level of depleted $\mathrm{UO}_{2}$ that will be investigated as the potential testing sample was valued for safety issue; a testing plan for measuring changes in stoichiometry of oxide fuels has been made and roadblocks for making measurements at high temperature have been pinpointed; in addition, collaboration with Boise State University (BSU) and Massachusetts Institute of Technology (MIT) has been established. In short, the capability of applying EIS for in-pile measurement of changes of fuels and cladding materials was initiated to be established. 


\section{CONTENTS}

EXECUTIVE SUMMARY .................................................... iii

ACRONYMS.................................................................... vi

1. Project Overview and Objective........................................... 1

2. Introduction................................................................... 1

2.1 Electrochemical Impedance Spectroscopy (EIS)...................... 1

2.2 Material Characterization Techniques............................... 2

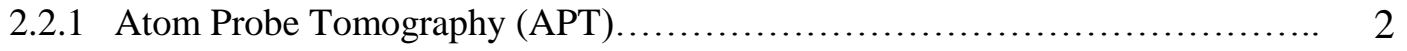

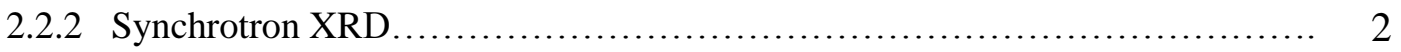

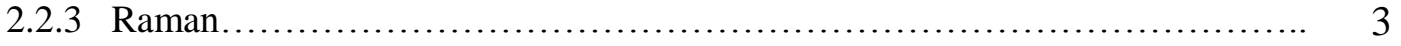

2.2.4 In-Situ Transmission Electron Microscopy (TEM) ...................... 3

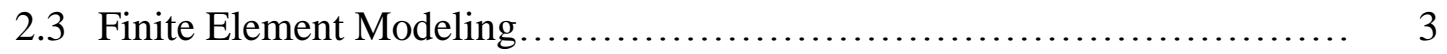

3. Experimental Design and Deployment at INL............................ 4

3.1 Laboratory Setting up.......................................... 4

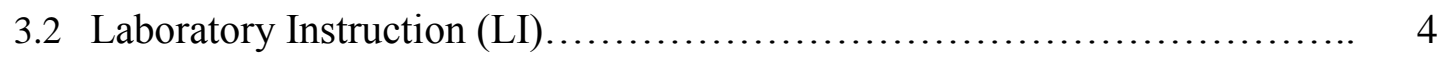

3.3 Major Equipment and Materials for the Laboratory..................... 4

3.4 Radiation Level................................................. 5

3.5 Conceptual Experimental System and Roadblocks..................... 5

3.6 Collaboration with Universities................................... 10

4. Research Plan............................................................... 10

5. Reference.................................................................... 11 


\section{FIGURES and TABLES}

Figure 1. Solartron potentiostat and tube furnace................................. 5

Figure 2. Original instrumentation diagram at uniform pressure..................... 7

Figure 2.1. Gas flow diagram for high $\mathrm{P}_{\mathrm{O} 2}$ flow at uniform pressure..................... 8

Figure 2.2. Gas flow diagram for low $\mathrm{P}_{\mathrm{O} 2}$ flow at uniform pressure........................... 8

Figure 3. Original instrumentation diagram for separately controlled pressure $\ldots \ldots \ldots \ldots \ldots \ldots . \quad 9$

Figure 3.1. Flow diagram for high $\mathrm{P}_{\mathrm{O} 2}$ for outside, while low $\mathrm{P}_{\mathrm{O} 2}$ for inside $\ldots \ldots \ldots \ldots \ldots \ldots \ldots \ldots . \quad 9$

Figure 3.2 Flow diagram for high $\mathrm{P}_{\mathrm{O} 2}$ for outside, while low $\mathrm{P}_{\mathrm{O} 2}$ for inside $\ldots \ldots \ldots \ldots \ldots \ldots \ldots \ldots$

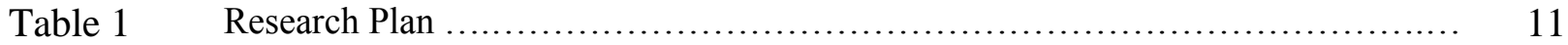




\section{ACRONYMS}

APT atom probe tomography

EIS electrochemical impedance spectroscopy

FE Finite element

TEM Transmission Electron Microscopy

XRD X-ray diffraction 


\section{Establishing New Capability of High Temperature Electrochemical Impedance Spectroscopy Techniques for Equilibrium and Kinetic Experiments}

\section{Project Overview and Objective}

In nuclear fuel, changes in structure and chemistry over the lifetime of the fuel can have a significant impact on fuel performance. In the early stage, point defects (Frenkel pairs, fission products) are created and the stoichiometry starts to change due to fission and subsequent irradiation damage. Also in this stage, the fuel density increases due to pore migration. In the mid stage, point defects start to diffuse, creating voids and causing dislocation growth, fission gas segregates to grain boundaries, and newly created fission gas bubbles start to form. In the late stage, the fuel starts to swell due to bubble nucleation and growth; fission gas is released into the plenum, and the fuel and cladding start to creep. Continued time in reactor leads to a buildup in the plenum pressure and ultimately to cladding failure. The structural integrity of the cladding is compromised by three primary mechanisms: (1) cladding embrittlement caused by pellet-cladding chemical interaction, (2) cladding embrittlement caused by hydride formation, and (3) wall thinning caused by excessive corrosion.

Structural and chemical evolution in reactor is driven by solid state chemical and thermal diffusion which are strongly influenced by the distribution of non-equilibrium defects (i.e. defect distribution that does not exist out-of-reactor). As an example consider oxygen diffusion in oxides fuels. Oxygen diffusion via the interstitial/vacancy mechanism in non-stoichiometric oxide fuel is orders of magnitude faster than its stoichiometric counterpart. Viewed from this perspective it is easy to understand how oxygen diffusion specifically and chemical diffusion in general can be significantly influenced by the non-equilibrium distribution of irradiation-induced defects. Because this defect distribution only exists in reactor, accurate measurement of chemical diffusion requires in-reactor measurements.

Currently, chemical evolution over the lifetime of the fuel can only be inferred using post-irradiation examination. In light of the discussion above, it is clear that this limitation presents a significant obstacle for achieving a comprehensive and unified understanding of chemical evolution. As an alternative to postirradiation measurements, electrochemical impedance spectroscopy (EIS) can provide an in-pile measurement of changes in chemistry in oxides and hydrides coupling with modeling such as finite element (FE) and other material characterization techniques such as atom probe tomography (APT), Raman spectroscopy, in-situ Transmission Electron Microscopy (TEM), and synchrotron X-ray microscopy.

The objective of this work package is to develop electrochemical impedance spectroscopic (EIS) techniques for the in-pile measurement of changes in solid state chemistry of fuels and materials in coupling with model simulation and material characterization. This work package will involve the initial development of electrochemical sensing technologies for measuring spatial- and time-resolved changes in fuel and cladding chemistry. Specific attention will be paid to monitoring changes in fuel stoichiometry, monitor cladding hydride formation and deformation, and cladding corrosion.

\section{Introduction}

\subsection{Electrochemical Impedance Spectroscopy}

Impedance like resistance is a measure of the ability of a circuit to resist the flow of electrical current, but unlike resistance, electrochemical impedance is usually measured by applying a small AC potential to an electrochemical cell and then measuring the response AC current through the cell, which can then be analyzed as a sum of sinusoidal functions (a Fourier series). The impedance is then represented as a complex number: 


$$
\mathrm{Z}(\omega)=\frac{E}{I}=\mathrm{Z}_{0} \exp (\mathrm{j} \phi)=\mathrm{Z}_{0}(\cos \phi+\mathrm{j} \sin \phi)
$$

Impedance data are commonly presented using Nyquist plot showing imaginary part in y-axis and real part on $\mathrm{x}$-axis of a plot and Bode plot showing frequency on $\mathrm{x}$-axis and absolute values of the impedance and the phase-shift on the y-axis. Many components can contribute to total impedance, including solution resistance, double layer capacitance, polarization resistance, charge transfer resistance, diffusion, coating capacitance etc.

Electrochemical Impedance Spectroscopy (EIS), also known as dielectric spectroscopy, is widely applied in the investigation of thermodynamic and kinetic properties of ceramics (oxides, carbides, and nitrides) at high temperatures. It is used to determine defect chemistry, chemical diffusions, and even solid-state reactions in-situ in real time at high temperatures ${ }^{1}$. Generally speaking, EIS is an experimental method for characterizing any electrochemical system, such as electrochemical cells, mass-beam oscillators, and even biological tissue (which possesses energy storage and dissipation properties). The technique measures the impedance of a system between two electrodes over a range of frequencies, typically from $1 \mathrm{mHz}$ to 1 $\mathrm{MHz}$; therefore, the frequency response of the system, including the energy storage and dissipation properties, is revealed. The technique has gained tremendous credibility over recent years and is now being widely employed in a variety of scientific fields, such as fuel cell testing, biomolecular interaction, and microstructural characterization. EIS often reveals information about the reaction mechanism and kinetics of an electrochemical process; different reaction steps will dominate at certain frequencies, the frequency response shown by EIS will help identify the rate-limiting step, and the change of impedance response (resistance and capacitance) at certain frequencies can help monitor the compositional and structural evolutions, such as the stoichiometry variations and defect diffusion, migration, and agglomeration.

\subsection{Material Characterization Techniques}

\subsubsection{Atom Probe Tomography (APT)}

APT will be used to reveal the atomic distribution of nuclear fuel, indicating the spatial distribution of element in non-stoichiometric oxide fuel. APT provides nano-scale surface, bulk and interfacial materials analysis of simple and complex structures with atom by atom identification and accurate spatial positioning. APT can provide quantitative information regarding the stoichiometry of clusters within the oxide fuel $^{2}$. In order to conduct APT analysis, APT needles will be fabricated using dual-beam focused ion beam. Samples will be cut at desired size and then mounted onto the silicon posts using platinum deposit and then milled to needle shape with tip radius $\leq 50 \mathrm{~nm}$. At the center for advanced energy studies (CAES) it has the most advanced 3-dimensional atom probe - Local Electrode Atom Probe (LEAP). With the LEAP, a high frequency voltage or a pulsed laser is applied to the needle-shaped sample to ionize and evaporate atoms from the sample surface, which are then accelerated towards a detector. The detector captures the location of incidence and the time-of-the-flight of the ion traveling from the pulse to the detector. The collected data include the spatial location of each incident ion and a spectrum of time-ofthe-flight measurement peaks, which allows for elemental identification.

\subsubsection{Synchrotron XRD}

High energy synchrotron X-ray microscopy and spectroscopies are powerful tools to determine the structure of hydride cladding and defects within oxide fuels. ${ }^{3}$ High energy synchrotron X-ray diffraction 
(XRD) has been proved to be efficient in determine different phases of hydride cladding and the reorientation of the hydride in irradiated nuclear fuel cladding. X-ray absorption near edge structure (XANES) and extended X-ray absorption fine structure (EXAFS) provide information on the long range and short range chemical disorder in addition to the oxidation state of the probed elements, which is useful to determine the order-disorder in non-stoichiometric oxide fuel. Bulk samples can be used in both technique with different thickness requirement. At the beamline 13 of Advanced Photon Source integrated synchrotron XRD and Raman measurements can be done on the same sample at elevated temperature or pressure.

\subsubsection{Raman}

Raman scattering is an inelastic photon scattering process. A Raman spectrum obtained from the surface of a Raman-active sample can be used to quantitatively determine material composition, stoichiometry, crystal quality, elastic strain, plastic deformation and material amount ${ }^{4}$. When used in conjunction with a microscope it is possible to obtain spatially resolved Raman spectra from the surface of a sample. A Renishaw microRaman microscope with $1 \mu \mathrm{m}$ spot size is available to study the ex-situ surface chemical changes to oxide chemistry and hydrides. Additionally, high-temp Raman is possible and will be implemented to allow oxide chemistries to be characterized in-situ for cladding and surrogate fuel materials.

\subsubsection{In-Situ Transmission Electron Microscopy (TEM)}

Transmission Electron Microscopy and Spectroscopy is a powerful tool for characterizing the chemical composition, atomic structure and micro-structure of materials, at Angstrom to few hundred nanometers scales $^{5}$. When external stimuli such as stress, electrochemical potential/current, temperature, radiation, and gas or liquid environment are applied to the material in real time, one can also monitor the chemical and structural changes in situ, revealing valuable information about the micro-mechanisms and kinetics of material transformations. TEM has been widely used in Post Irradiation Examinations (PIE), but is also used in conjunction with in situ ion radiation. Processes such as oxidation, hydride formation, cracking, dislocation-gas interaction, interfacial decohesion, liquid-solid interactions and corrosion, etc. have been studied with in situ TEM. There is a natural synergy between TEM characterization and atomistic and first-principles modeling, as they work at basically the same length scale, and can be used to cross-check each other. The in situ TEM can be used to calibrate the algorithms of accelerated-timescale atomistic simulations, which provides energetic as well as structural information. This powerful combination allows for complete understanding of what happens in the material at few hundred nanometers scale and below.

\subsection{Finite Element Modeling}

The Finite Element Method (FEM) is a numerical technique for finding approximate solutions to boundary value problems. FEM has been used for reactor fuels modelling for many years. It is most often used for fuel performance modelling at the pellet and pin scale, however, it has also been used to investigate properties of the fuel material, such as thermal conductivity and fission gas release. Recently, the United Stated Department Nuclear Energy Advanced Modelling and Simulation Program has begun using FEM as the basis of the MOOSE-BISON-MARMOT Project that is developing a multidimensional, multi-physics fuel performance capability that is massively parallel and will use multi-scale material models to provide a truly predictive modelling capability. ${ }^{6}$ The proposed project will develop a theoretical and modeling framework to interpret EIS experiments for nuclear fuel materials. A generic descriptors for polyphase (including porous) polycrystalline microstructures will be built. Transport equations based on the starting local properties will be set up, and these transport equations using 
MOOSE under different boundary conditions for different frequency inputs will be solved. The MOOSE based finite element code as well as microscopic identification of defects and transport carriers will be used to help interpret the experimental EIS data.

\section{Experimental Design and Deployment at INL}

\subsection{Laboratory Setting up}

Several potential lab spaces in the building of EIL and IRC at INL were checked starting from July 2017. After discussion with Lab Manager Sandy Fox and Lab Space Coordinator David Reed, the IRC Lab B-1 fits the purpose of this project and was assigned to this project for conducting experimental work. And it was cleaned up and ready for use at Aug 22, 2017. Some equipment is setting up in the lab now.

\subsection{Laboratory Instruction (LI)}

The Laboratory Instruction (LI) for this project was drafted starting at August 2017 working with Sandy Fox as the Lab Manager and Dr. Tedd Lister as the Principal Researcher. At beginning, the LI was started for fuel chemistry using $\mathrm{UO}_{2}$ as the testing samples. However, considering much longer time needed for $\mathrm{LI}$ approval with $\mathrm{UO}_{2}$ due to more strict safety regulations related to radiative materials, we started a LI with surrogate oxide samples $\left(\mathrm{CeO}_{2}\right.$, and $\left.\mathrm{BaCeO}_{3}\right)$ first in order for experiments to start early. This LI is in final review right now and will get approved soon. After approval of this LI, we will revise it by including radiative samples later on for $\mathrm{UO}_{2}$ fuel experiments scheduled on early 2018.

Ceria $\left(\mathrm{CeO}_{2}\right)$ and $\mathrm{BaCeO}_{3}$ are selected as the surrogate oxide samples for EIS measurement due to their unique characteristics. Ceria is often used as a surrogate for $\mathrm{UO}_{2}, \mathrm{PuO}_{2}$ and a representative ceramic for spent fuel $\mathrm{UO}_{2}$ pellets for studying the material properties of the fuel oxides, since ceria possesses identical structure and has similar thermophysical properties such as density and melting point. ${ }^{3}$ It is much easier, safer, and far less expensive to conduct as many tests as possible using non-radioactive, then slightly radioactive surrogates than radioactive fuels.

$\mathrm{BaCeO}_{3}$ belongs to a group of high temperature protonic conductors in moist atmosphere when doped with trivalent cations such as $\mathrm{Y}^{3+}$ and $\mathrm{Gd}^{3+7,8}$. Its non-stoichiometry in the compound can be varied by equilibrating under well defined oxygen partial pressure at high temperatures or by doping with trivalent cations $^{8,9}$.

Some training listed in the LI are pre-required to do experiments and I have finished the following training: 00INL72P INL Radworker 1, 00INL670 Lab Access Training, 0INL1491 Laboratory Ergonomics, 000INL13 Chemical Hygiene, 0INL1041 Compressed Gas Safety, SMJS992B, Flammable/Combustible, QN000PSA: Pressure System Assembler, IGET0000 INL General Employee Access.

Since safety is always the priority in doing research at INL, Risk and Controls is one of the core part in the LI. Various risks are identified and corresponding controls (Engineering and Administrative Controls) are explored for conducting the experiment in this LI.

\subsection{Major Equipment and Materials for the Laboratory}

Major equipment and materials were ordered and the following were delivered: 
- Solartron Potentiostat with frequency response analyzer (EnergyLab XM), 2 A booster with 4 additional Aux channels (Figure 1).

- Split Tube Furnace (Applied Test System, 3420-2-16-12), up to $1500{ }^{\circ} \mathrm{C}$ with 2" OD process tube (Figure 1).

- Pt wires as electrode and pastes for EIS measurement.

- Oxygen, nitrogen and hydrogen gas cylinders.
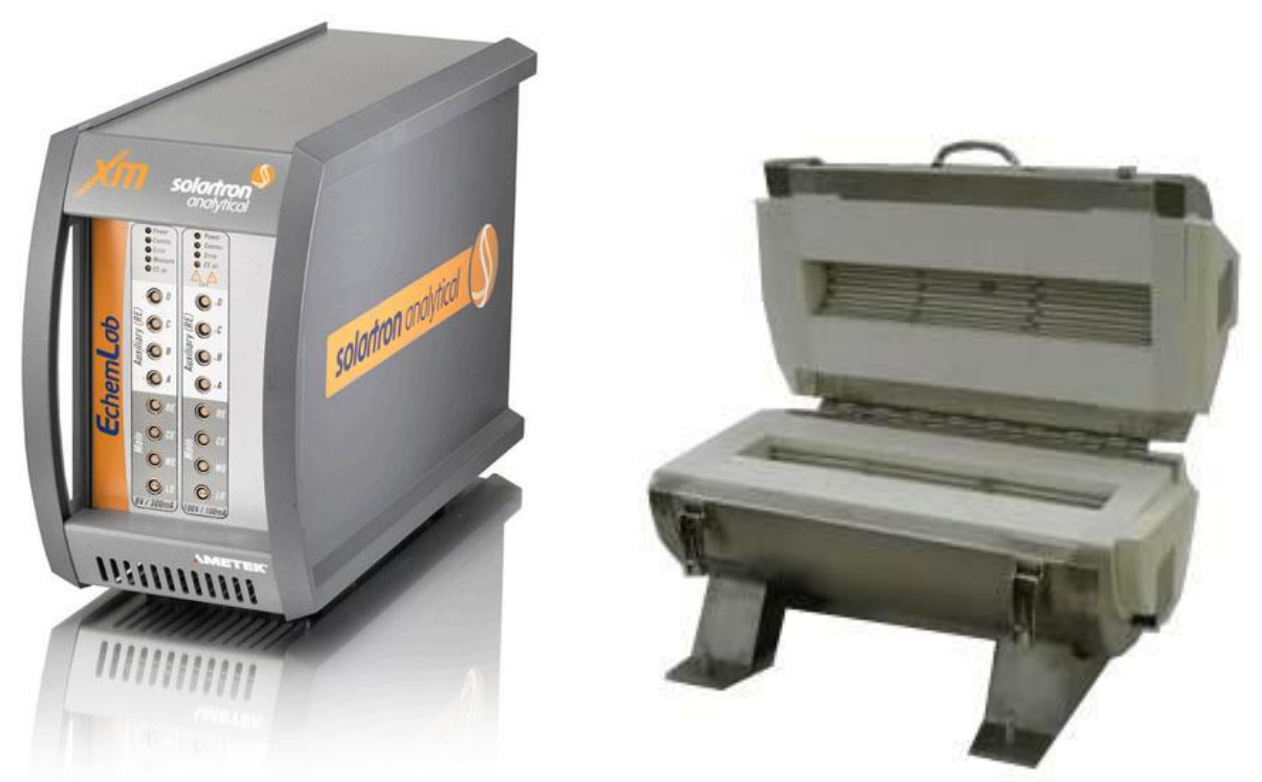

Figure 1. Solartron potentiostat and tube furnace

\subsection{Radiation Level}

Two RADCon (radiation control) forms 441.47 and 441.A59 were sent to Rad Engineer, Todd Echeverria at INL on July 20, 2017 for evaluation and determination what radiological requirements will be need for the project. Based on the fuel sample, depleted $\mathrm{UO}_{2}$ pellets with a dimension of about $5 \mathrm{~mm}$ ID by $1 \mathrm{~mm}$ height, Todd reviewed and calculated that the radiation level of this project is lower than $0.12 \mathrm{mrem}$, belong to set 1, benchtop control, which is the lowest level of radiation in INL's RAD Control category.

\subsection{Conceptual Experimental System and Roadblocks}

A testing plan for measuring changes in stoichiometry of oxide fuels has been made and roadblocks for making measurements at high temperature have been pinpointed. The sample pellets used in this study will be $\mathrm{CeO}_{2}, \mathrm{BaCeO}_{3}$, or zirconium-based alloys with a dimension of about 3-10 mm ID by 1-5 mm height. They will be purchased online or obtained from other laboratories and used as received. The experimental procedures are same for all materials. Optimal experimental procedures and parameters, such as oxygen partial pressure, process temperature, and scanning frequency will be explored.

Setting up the experimental system by connecting gas cylinders (pure $\mathrm{O}_{2}, \mathrm{~N}_{2} \operatorname{tank} 1$ and 2, and 3\% $\mathrm{H}_{2}$ balanced with $\mathrm{N}_{2}$ ) and gas tubes to the reactor in the furnace, as shown in Figure 2 and 3. The tube 
systems in Figure 2 and 3 are same outside the furnace, while the reactor figuration inside the furnace is different.

The system in Figure 2 is to provide uniform gas pressure for the testing sample, while the system in Figure 3 can control gas pressure separately for both sides of the sample. Taking Figure 2 as an example to describe the process flow from inside to outside. The reactor is a 2" OD process tube setting inside a split Tube Furnace, which can be up to $1500{ }^{\circ} \mathrm{C}$. The pellet oxide is mounted inside the reactor and its impedance will be measured at different temperature $\left(800-1200{ }^{\circ} \mathrm{C}\right)$ and different oxygen partial pressure $\left(10^{-25}-1 \mathrm{~atm}\right)$. Various temperatures will be obtained by controlling the furnace. The hydrogen concentration in the whole system is always lower than $0.1 \%$.

Different oxygen partial pressure will be achieved through gases mixing or water vapor dissociation. Oxygen and nitrogen connected to provide higher oxygen partial pressure $\left(10^{-3}-1 \mathrm{~atm}\right)$ by adjusting the $\mathrm{N}_{2} / \mathrm{O}_{2}$ mixing ratio through mass flow controllers. Low $\mathrm{P}_{\mathrm{O} 2}\left(10^{-25}-10^{-15} \mathrm{~atm}\right)$ are generated by varying the $\mathrm{H}_{2} / \mathrm{N}_{2}$ ratio at a constant water vapor pressure of $2 \times 10^{-4} \mathrm{~atm}$. The constant water vapor pressure is maintained by a water bubbler, where the $\mathrm{H}_{2} / \mathrm{N}_{2}$ mixture goes through. The $\mathrm{P}_{\mathrm{O} 2}$ is calculated from the $\mathrm{P}_{\mathrm{H} 2}$, $\mathrm{P}_{\mathrm{H} 2 \mathrm{O}}$ and the equilibrium constant for water vapor dissociation at the measurement temperature.

Since the system in Figure 2 is to provide uniform pressure for the sample, the shut off valve \#3 and 4, and three-way valve 1 are always closed, which are only for separately controlled gas. When operating at high $\mathrm{P}_{\mathrm{O} 2}$ as shown in Figure 2.1, oxygen and nitrogen \#1 cylinders are open, while 3\% hydrogen cylinder and nitrogen \#2 are closed. Shut off valve \#1 and 2 are open, while shut off valve \#5 is closed. And the three-way valve \#2 facing the hydrogen side is closed, only oxygen and nitrogen is going through the pipes to feed in.

When operating at lower $\mathrm{P}_{\mathrm{O} 2}$ as shown in Figure 2.2, oxygen and nitrogen $\# 1$ cylinders are closed, while $3 \%$ hydrogen cylinder and nitrogen \#2 are open. Shut off valve \#1 and 2 are closed, while shut off valve \#5 is open. And the three-way valve \#2 facing the oxygen side is closed, only hydrogen and nitrogen is going through the pipes to feed in

During operation, oxygen and hydrogen gas will not be used at the same time. Between each experiment with different oxygen pressure, the pipes are flushed by pure nitrogen to remove previous oxygen residues.

If the off gas temperature exiting from the furnace is higher than $50^{\circ} \mathrm{C}$, the gases are passed through a water cooling jacket to reduce temperature to lower than $50^{\circ} \mathrm{C}$. After passing through the cooling jacket gases will be vented to the hood. A provision to capture a small volume of gas ( $<1$ Liter) into a Tedlar bag for transport for GC analysis in another laboratory. Vented gases will contain lower than $0.1 \%$ hydrogen.

Figure 3 shows the tube system for separately controlled oxygen pressure for each side of pellet samples. The sample will be mounted at the end of a smaller (about 3/8") ceramic tube, and is gas tight. Then the gas pressure for the outside and inside of the smaller tube can be controlled separately. For example, in order to achieve high $\mathrm{P}_{\mathrm{O} 2}$ for the outside of the pellet sample, while low pressure for the inside, the following procedure will be followed as shown in Figure 3.1: all the four gas cylinders are open; for oxygen side, shut off valve \#1, 3 are open, while valve \#2 is closed. The three-way valve \#1 facing the hydrogen side is closed, only oxygen is going through the pipes to feed in. For the hydrogen side, the shut valve \#5 is open, while valve \#4 is closed. The three-way valve \#2 facing the oxygen side is closed, only hydrogen is going through the pipes to feed in. 
On the other hand, in order to achieve low $\mathrm{P}_{\mathrm{O} 2}$ for the outside of the pellet sample, while high pressure for the inside, the following procedure will be followed as shown in Figure 3.2: all the four gas cylinders are open; for oxygen side, shut off valve \#1, 2 are open, while valve \#3 is closed. The three-way valve \#2 facing the hydrogen side is closed, only oxygen is going through the pipes to feed in. For the hydrogen side, the shut valve \#4 is open, while valve \#5 is closed. The three-way valve \#1 facing the oxygen side is closed, only hydrogen is going through the pipes to feed in.

The system in Figure 3 will be used to investigate hydride formation of zirconium-based alloys. $\mathrm{BaCeO}_{3}$ or other proton conduction oxides are coated on each side of the pellet for form an electrochemical cell. The coating process will be formed by applying Pt paste to the surfaces of the pellet samples and firing at $1500{ }^{\circ} \mathrm{C}$ for $4 \mathrm{~h}$ in oxygen in a hood. The gas pressure at each side can be adjusted separately controlled. The oxygen pressure is less than 2 atm on both sides.

The rim of a pellet was grooved at $90^{\circ}$ intervals and four Pt wires of thickness $0.25 \mathrm{~mm}$ are used to connect pellet samples with the impedance spectroscopy instrument . Electrical contacts will be formed by applying Pt paste to the surfaces of the pellet samples and firing at $1500{ }^{\circ} \mathrm{C}$ for $4 \mathrm{~h}$ in oxygen. The impedance spectra is to be recorded in the frequency range between $20 \mathrm{~Hz}$ and $1 \mathrm{MHz}$ at an applied signal of $200 \mathrm{mV}$, which will used for calculation of conductivity.

Before measurements are accepted, the phase angle of the impedance is automatically checked to ensure that it is below $2^{\circ}$. Resistance are converted to conductivities in post experiment data analysis using related equations. When the gas composition is changed readings stabilized after $20 \mathrm{~min}$ in $\mathrm{N}_{2} / \mathrm{O}_{2}(1-2 \mathrm{~h}$ in $\mathrm{H}_{2} / \mathrm{N}_{2}$ ), thereafter becoming repeatable to the third decimal figure.

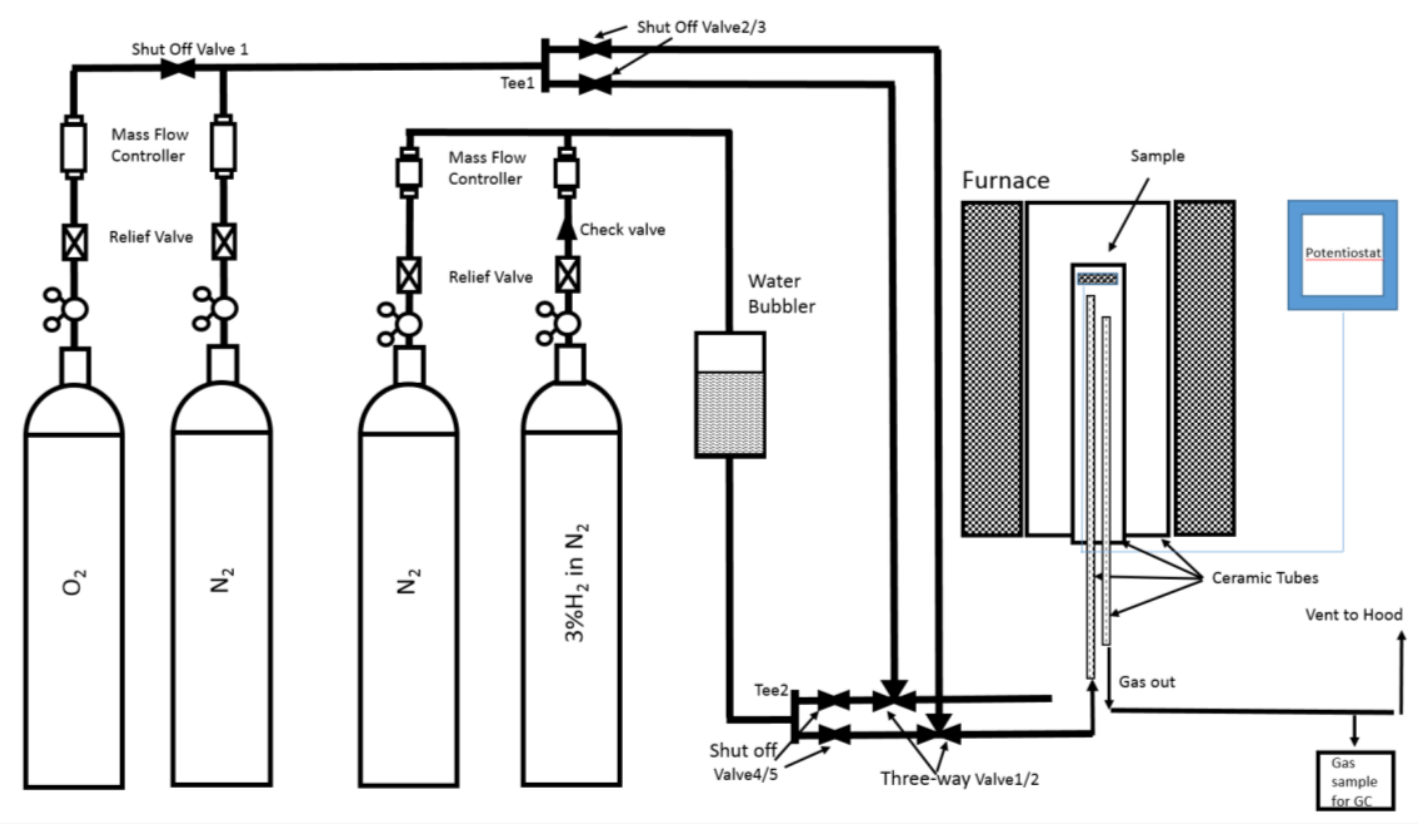

Figure 2. Original instrumentation diagram at uniform pressured 


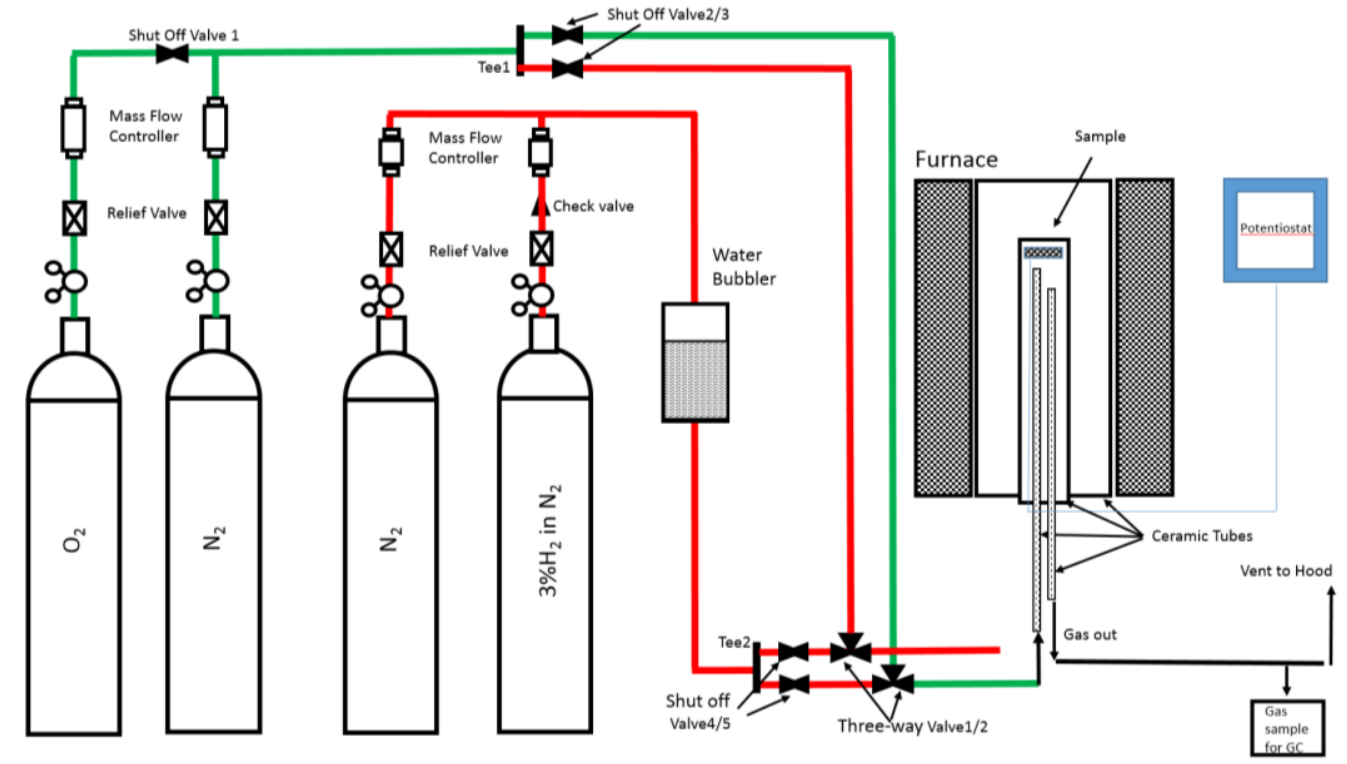

Figure 2.1. Gas flow diagram for high $\mathrm{P}_{\mathrm{O} 2}$ flow at uniform pressure

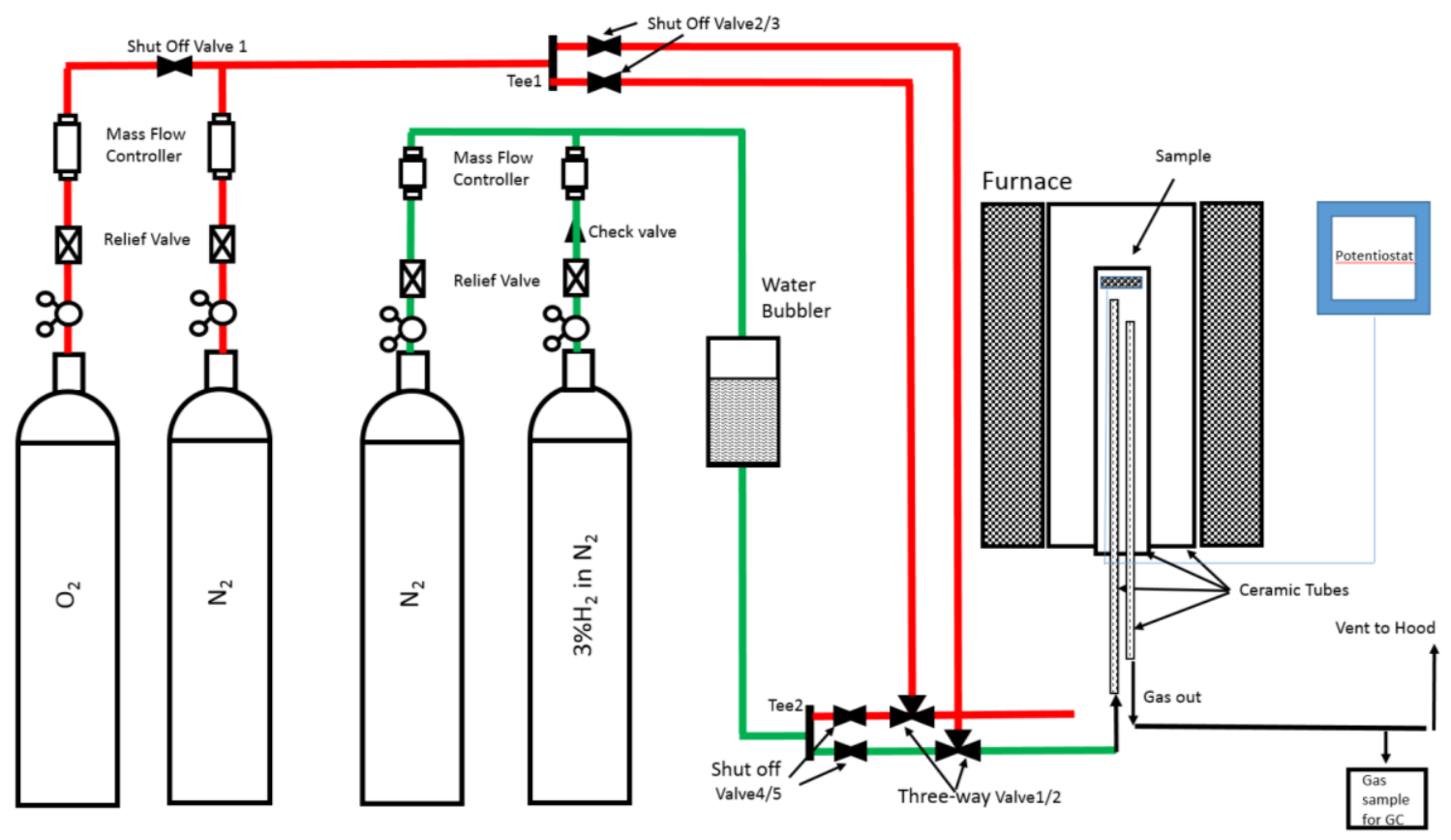

Figure 2.2. Gas flow diagram for low $\mathrm{P}_{\mathrm{O} 2}$ flow at uniform pressure 


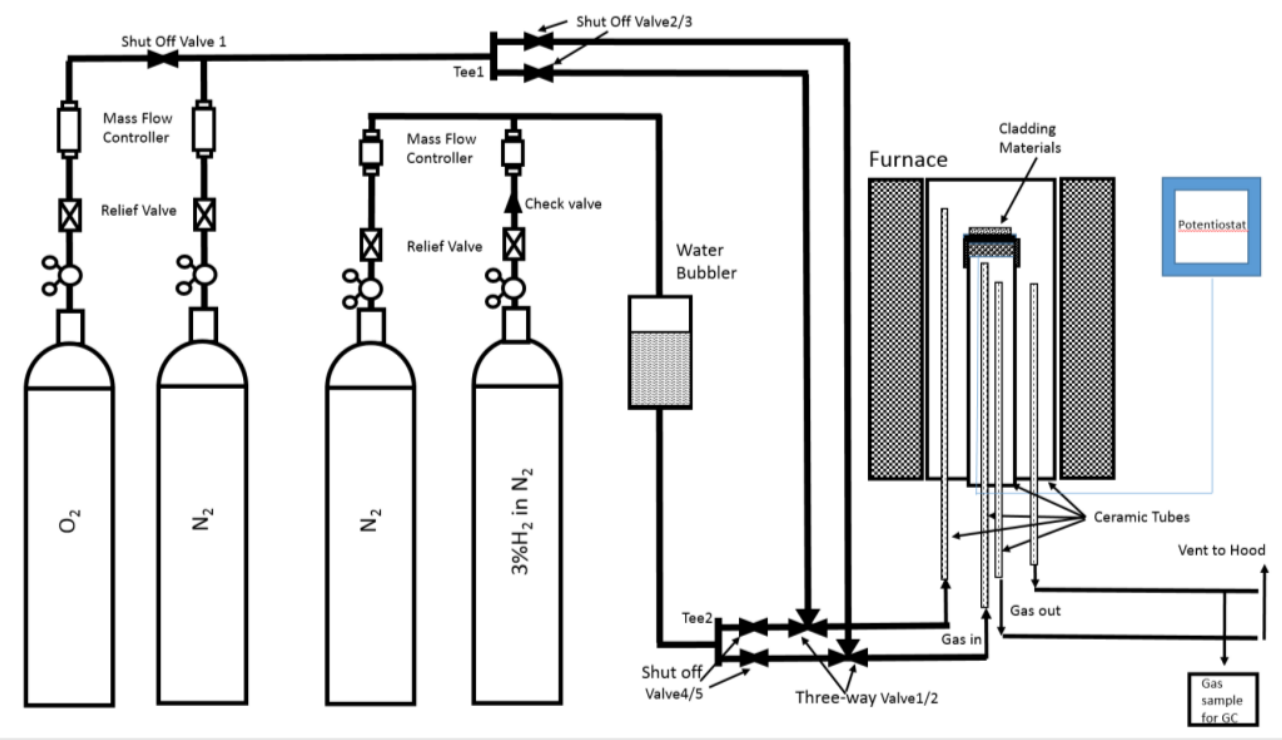

Figure 3. Original instrumentation diagram for separately controlled pressure on two sides of a sample

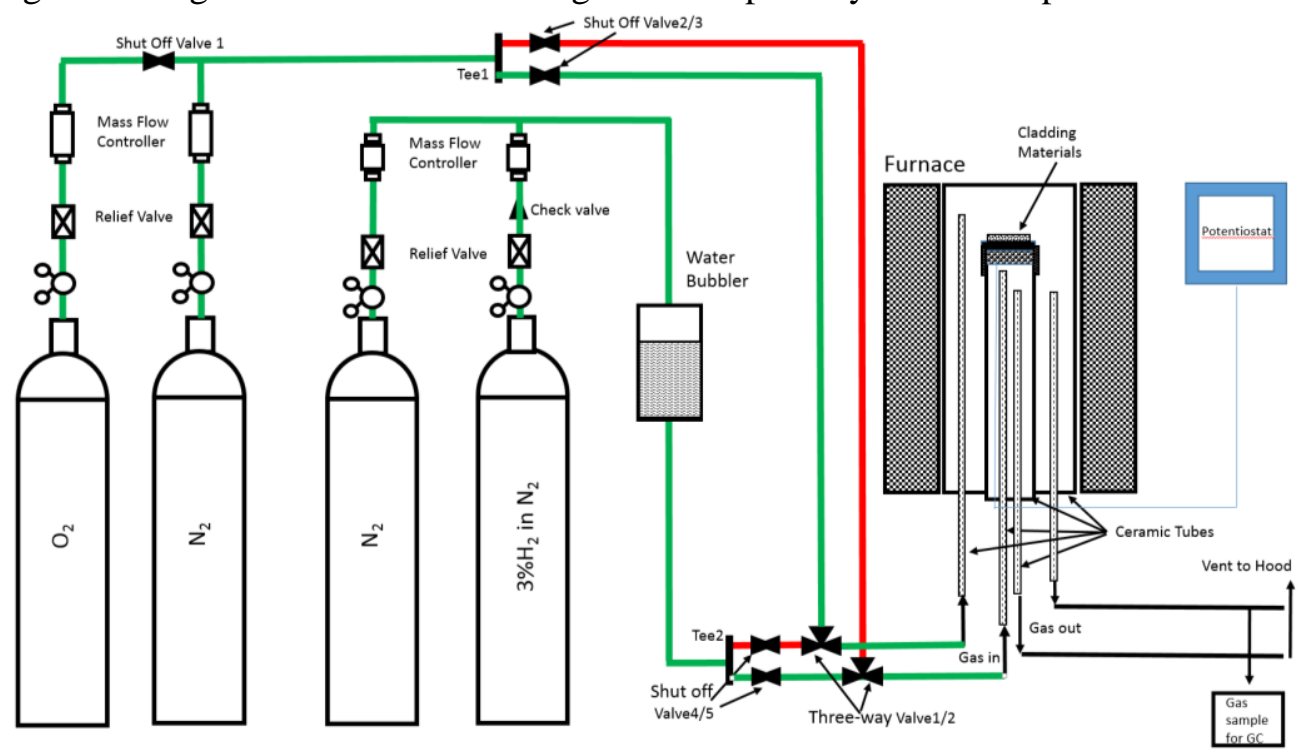

Figure 3.1. Gas flow diagram for high $\mathrm{P}_{\mathrm{O} 2}$ for outside, while low pressure for inside of the sample 


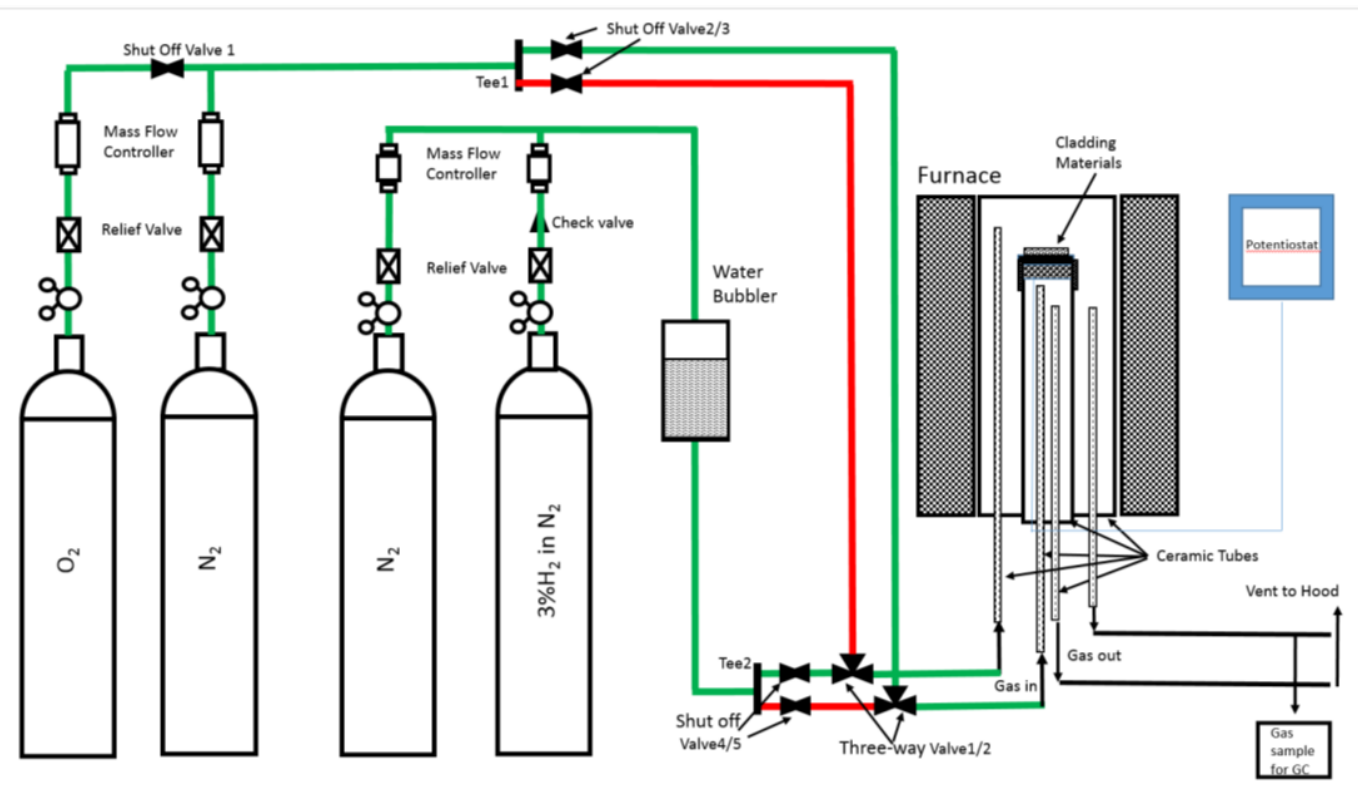

Figure 3.2. Gas flow diagram for low $\mathrm{P}_{\mathrm{O} 2}$ for outside, while high pressure for inside of the sample

\subsection{Collaboration with Universities}

A subcontract with Dr. Claire Xiong, Dr. Mike Hurley at BSU has been established to develop advanced microscopic characterization of non-stoichiometric uranium oxide fuel and surrogate fuel samples using atom probe tomography (APT), Raman spectroscopy, and synchrotron X-ray microscopy and spectroscopies.

A second subcontract is undergoing with $\mathrm{Dr}$. Ju Li at MIT to develop a finite element model for the impedance response of porous materials.

\section{Research Plan}

There are three tasks in this project and the proposed research activities for each task are listed as in the Table 1. 


\begin{tabular}{|c|c|c|}
\hline $\mathbf{R} \& \mathbf{D}$ & & Tasks \\
\hline \multirow{3}{*}{$\begin{array}{c}\text { Fuel } \\
\text { Stoichiometry }\end{array}$} & FY17 & $\begin{array}{l}\text { - Establishing high temperature EIS capability and electrochemical reactor for equilibrium and kinetic } \\
\text { experiments (INL) } \\
\text { - Developing research plan and capabilities (BSU) }\end{array}$ \\
\hline & FY18 & $\begin{array}{l}\text { - Measuring fuel stoichiometry as a function of temperature under thermodynamic equilibria (INL) } \\
\text { - APT tomography of spatial distribution of element in non-stoichiometric oxide fuel samples (BSU) } \\
\text { - Raman characterization of surface stoichiometry of oxide fuel samples at elevated temperatures (BSU) } \\
\text { - FE modeling of dielectric response of vacancies (MIT) }\end{array}$ \\
\hline & $\begin{array}{l}\text { FY19 } \\
- \\
\text { FY21 }\end{array}$ & $\begin{array}{l}\text { - Measuring chemical diffusion of oxygen vacancies at high temperatures (INL) } \\
\text { - Measuring fuel stoichiometry under irradiation at high temperatures (INL) } \\
\text { - Developing dielectric response model under irradiation (MIT) } \\
\text { - Synchrotron characterization of redox state changes of oxygen in fuel to quantitatively determine the } \\
\text { stoichiometry of the fuel and comparing with electrochemical method (BSU) } \\
\text { - Integrating the sensor for demonstration (INL) }\end{array}$ \\
\hline \multirow[b]{3}{*}{$\begin{array}{l}\text { Cladding } \\
\text { Hydride } \\
\text { Formation }\end{array}$} & FY17 & $\begin{array}{l}\text { - Constructing high temperature electrochemical testing system and reactors with separately controlled } \\
\text { anode and cathode gas atmospheres (INL) } \\
\text { - Developing FE model for porous media (MIT) }\end{array}$ \\
\hline & FY18 & $\begin{array}{l}\text { - Fabricating electrochemical cells consisting of cladding metal with proton conducting ceramics and } \\
\text { performing in-situ hydride electrochemical formation (INL) } \\
\text { - In-Situ TEM characterization of delayed hydride cracking (MIT) } \\
\text { - Synchrotron characterization of the structure of cladding hydride (BSU) } \\
\text { - Raman characterization of the surface of cladding hydride (BSU) }\end{array}$ \\
\hline & $\begin{array}{l}\text { FY19 } \\
- \\
\text { FY21 }\end{array}$ & $\begin{array}{l}\text { - Performing electrochemical hydride dealloying at high temperatures and determining kinetics of hydride } \\
\text { formation and dealloying (INL) } \\
\text { - Measuring impedance response of Zr-4 cladding with various hydride volume fraction (INL, MIT) } \\
\text { - In-situ high temperature TEM visualization of microstructure evolution of cladding during hydride } \\
\text { formation and dealloying (MIT) } \\
\text { - Tomography of cladding before and after hydride formation and post deaaloying (BSU) } \\
\text { - Raman characterization of hydrogen in- and out- diffusion at elevated temperatures (BSU) } \\
\text { - Developing strategy for mitigating hydride formation (INL) } \\
\text { - Neutron/gamma irradiation tolerance testing at MIT-NRL (MIT, INL) } \\
\text { - Demonstrating hydride mitigation technology (INL) }\end{array}$ \\
\hline \multirow{3}{*}{$\begin{array}{l}\text { Fission Gas } \\
\text { Diffusion }\end{array}$} & FY17 & - No activity \\
\hline & FY18 & - Developing strategy, methods and plan to measure fission gas diffusion (INL) \\
\hline & $\begin{array}{l}\text { FY19 } \\
- \\
\text { FY21 }\end{array}$ & $\begin{array}{l}\text { - Measuring fission gas in-diffusion induced dielectric variation of fuel pellets at high temperatures (INL) } \\
\text { - FE modeling of EIS of fission gas diffusion at high temperatures (MIT) } \\
\text { - Tomography of fuel pellet before and after fission gas in-diffusion (BSU) }\end{array}$ \\
\hline
\end{tabular}

\section{References}

1. M.E. Orazem and B. Tribollet. 2008. Electrochemical Impedance Spectroscopy. John Wiley \& Sons Inc. Hoboken, New Jersey.

2. T.F. Kelly and M.K. Miller. 2007. Invited Review Article: Atom Probe Tomography. Review of Scientific Instruments 78, 031101 (2007)

3. H. He et al., Electrochimica Acta, 92 (2013), 148.

4. Y. Zhang et al., Current Opinion In Solid State and Materials Science, 19 (2015), 19.

5. Williams D.B., Carter C.B. (1996) The Transmission Electron Microscope. In: Transmission Electron Microscopy. Springer, Boston, MA

6. M.R. Tonks, R. Williamson, and R. Masson. 2015. Chapter 22: Finite Element Modelling. NEA/NSC/R (2015)5. http://www.iaea.org/inis/collection/NCLCollectionStore/_Public/47/032/47032428.pdf

7. A.K. Tyagi and S. Banerjee. 2017. Materials Under Extreme Conditions: recent trends and future prospects. Technology \& Engineering. Elsevier.

8. K.D. Kreuer, Th. Dippel, Yu.M. Baikov and J. Maier, Solid State Ionics 86-88 (1996), 613.

9. T. He, K.D. Kreuer, Yu.M. Baikov and J. Maier, Solid State Ionics 95 (1997),301 